\title{
Examining Engagement in the Discussion Section of Marketing Research Articles
}

\author{
Alaa Alzahrani \\ Department of English Language \& Literature, College of Arts, King Saud University, Riyadh, Saudi Arabia
}

Received May 7, 2020; Revised June 12, 2020; Accepted June 23, 2020

Copyright $\bigcirc 2020$ by authors, all rights reserved. Authors agree that this article remains permanently open access under the terms of the Creative Commons Attribution License 4.0 International License

\begin{abstract}
Studies have shown that the use of Engagement resources is a subtle task for research article writers, making the appropriate use of such resources a complex topic for less experienced writers. For this reason, the present study examined expert writers' ways of positioning their work in marketing research articles on Discussion sections to highlight how Engagement resources can be managed successfully. Drawing on the Engagement subsystem of the Appraisal Framework nine Discussion sections were analyzed both quantitatively and qualitatively using the UAM corpus tool. The analysis revealed that the Discussion sections were highly heteroglossic, and had contractive resources twice as much as expansive ones, suggesting that marketing academics are more concerned with establishing their credibility as knowers in the field than construing a reader-friendly text. It is also observed that academics in the marketing field tend to focus more on proclaiming their findings in the Discussion section while at the same time mitigating the communicative force of their argument by using tentative language, creating a subtle balance between claim-making and acceptance of potentially differing views. The findings of the present study can offer insights for academic writing materials' developers, novice researchers, and academic writing instructors.
\end{abstract}

Keywords The Appraisal Engagement Framework, Discourse Analysis, Research Article Discussion Sections

\section{Introduction}

It has been established that writing research articles involves interaction between writers and readers rather than stating experimental facts (Hyland, 2005). This interactional and dialogical view of academic writing is based on the idea that almost all texts are written as a response to other texts and thus a piece of writing may need to build on, and at the same time, challenge earlier texts (G. Thompson, 2001; White, 2011). Therefore, it is highly likely that researchers will engage in their articles with prior works as well as their audience to make them accept the presented findings. One way to accomplish this task is through the use of Engagement resources (Martin \& White, 2005); thus, helping academic writers in arguing for the validity of their findings, which may conflict with prior validated knowledge to establish a space for their contribution in the field. Such Engagement resources are found to be particularly common in the highly dialogic Discussion sections whereby authors attempt to convince readers of the contribution being made; for example, by highlighting differences and similarities between the resulting findings and previous works (e.g., Fryer, 2013). Nevertheless, studies have shown that the use of Engagement resources is a complex and subtle task for research article writers as they need to include such resources to simultaneously balance between asserting their argument, acknowledging alternative views to it and predicting readers response to that argument (Cheng \& Unsworth, 2016; Loi, Lim, \& Wharton, 2016; D. K. Thompson, 1993). Therefore, this study examined the patterns and functions of Engagement resources in Discussion sections to highlight its effective use in textually positioning new research in the field and establish its validity. Understanding the successful application of such interpersonal linguistic choices can provide practical implications for teaching academic writing.

\section{Literature review}

\section{The Engagement System}

The system of Engagement was proposed by Martin and White (2005) under the appraisal theory. What makes this system particularly suitable for the analysis conducted in the present study is that it provides extensive categories 
which allow a fine-grained analysis of how research article writers position their work in relation to prior related research. According to Martin and White (2005), the Engagement system distinguishes between two types of utterances: monoglossic (single-voiced) and heteroglossic (multi-voiced) utterances. Every utterance can be either described as monoglossic or heteroglossic, depending on how the writer presented his/her opinion. Monoglossic sentences involve bare assertions of views in which writers ignore any alternative voices, presupposing readers' agreement with the writer's position. In contrast, heteroglossic sentences acknowledge the existence of different opinions in which the writer mentions them to challenge and limit the scope of alternative positions (i.e., contract) or to make space for such text external voices (i.e., expand).

As seen above, heteroglossic utterances seem to serve two main functions, and thus they are divided into two main categories that of (1) contract and (2) expand. Writers can use both contract and expand resources to bring in other voices to their texts to represent alternative opinions regarding the topic at hand. Although contract and expand both involve acknowledgement of alternative voices, they differ in the degree to which they accept such voices. While the contract category pertains to utterances that acknowledge divergent voices only to refute them, those that expand do so but without refuting, opening and expanding the space for negotiation.

The contract category is further subdivided into two components that of disclaim and proclaim. Disclaim covers linguistic items that directly reject the opposing view through sources of (1) deny (e.g., no, don't) and (2) counter (e.g., however). Unlike disclaim, proclaim items limit the space for alternative positions/voices by using less direct linguistic expressions in comparison to disclaim. Proclaim expressions are classified into four subtypes that of (1) concur, (2) pronounce, (3) endorse, and (4) justify. Using these, the writer can restrict the scope of negotiation by overtly indicating agreement with a certain position and presenting it as a commonly shared one (concur), by overtly siding with an external voice that is represented as correct and highly credible (endorse), by strongly emphasizing the reliability of his/her proposition (pronounce), or by providing justifications for an utterance (justify).

On the other hand, the expand category, which opens up rather than closes down the dialogic space, is subdivided into two types: entertain and attribute. Entertain estimates the likelihood of a proposition, and it is realized through modal auxiliaries (e.g., may, would, must), modal adjuncts (e.g., perhaps, probably), modal attributes (e.g., it's likely that) or evidence-based formulations (e.g., it seems). The other dialogic expansive subtype is an attribute that describes linguistic expressions that introduce an external source to the text commonly realized through explicit in-text citations. Attribute formulations are further classified as (1) acknowledgment and (2) distance. Writers can include the external source without showing their approval/disapproval of it (acknowledge) or they can show their explicit disapproval (distance).

\section{Studies on Engagement in Academic Writing}

The use of Engagement in academic writing has been mostly examined in the production of student writers (e.g., Chatterjee, 2008; Geng, 2015; Geng \& Wharton, 2016; Loghmani, Ghonsooly, \& Ghazanfari, 2020; Mei \& Allison, 2007; Oskoz, Gimeno-Sanz, \& Sevilla-Pavón, 2018; Ryshina-Pankova, 2014; Widhiyanto, 2017), with comparatively fewer studies focusing on research writers (e.g., Cheng \& Unsworth, 2016; Fryer, 2013; Loi et al., 2016; Pascual \& Unger, 2010; Xu \& Nesi, 2019). Although the important role of Engagement resources in producing a more successful piece of writing has been attested in certain academic genres such as doctoral and undergraduate dissertations (Chatterjee, 2008; Geng \& Wharton, 2016; Loghmani et al., 2020; Widhiyanto, 2017), this role has been relatively underexplored in the research article genre as, thus far, only four studies considered published articles.

A general finding in research on students' use of Engagement resources in doctoral discussions is the higher frequency of items that contract dialogue (e.g., in spite of these findings) compared to those expanding it (e.g., these findings may). For instance, Geng and Wharton (2016) examined Engagement choices in 12 doctoral Discussions written in English by native and Chinese non-native students. They found no statistically significant differences in such choices as both groups included more contractive items $(75 \%)$ than expansive ones $(25 \%)$, suggesting that being native or non-native does not affect the writer's use of Engagement resources. Similar results were reported in Loghmani, Ghonsooly and Ghazanfari (2020) who analyzed the frequency and function of Engagement items in ten doctoral dissertations' Discussion sections written by native English Ph.D. students in the field of TEFL, revealing the students' preference of dialogically contractive Engagement strategies which account for $61 \%$ of all instances of Engagement. The predominance of contractive statements that close the dialogue in both studies is seen as an attempt to guard against possible rejections or challenges raised by dissertation examiners, showing that contractive resources are one linguistic tool for securing readers' acceptance as such resources acknowledge alternative views for the purpose of refuting them.

On the other hand, mixed findings were reported in the literature on experienced academic writers' employment of Engagement options. This body of research investigated how established writers utilize Engagement choices in two genres that of the research article and grant proposals. The most commonly used heteroglossic Engagement resources 
were reported to be contractive in some studies (e.g., Cheng \& Unsworth, 2016; Loi et al., 2016) while others found more expansive than contractive items (e.g., Fryer, 2013; Pascual \& Unger, 2010; Xu \& Nesi, 2019). These studies will be reviewed in the remaining part of this section to show the potentials of an engagement-based analysis in identifying the interpersonal language choices used by expert writers.

A comparative study was conducted by Loi et al., (2016), who examined the communicative functions and the appraisal features of English and Malay research article Conclusions in the field of psychology. The frequency analysis of Engagement options revealed that contraction constitutes $67 \%$ of all heteroglossic statements in the two examined groups. A further relevant finding to the present study is that English conclusions, unlike the Malay ones, had a subtle balance of assertion and mitigation, suggesting that the English writers are more skilled in advancing an argument, and thus more able to convince others of the validity of their claims. This finding indicates that the successful use of Engagement resources does not depend on their frequency in the text, but rather on the writer's ability to manage the balance between these resources. Although the paper offered an overall picture of the role of appraisal resources in writing research article conclusions, it did not provide a detailed analysis of Engagement strategies as the purpose of the study was to analyze both Engagement resources and the communicative functions of the Conclusion sections.

Likewise, Cheng and Unsworth (2016) analyzed the Discussion sections of 21 Applied Linguistics research articles to examine the use of interpersonal resources in representing and negotiating conflict. It was found that contractive resources $(\sim 57 \%)$ are used predominantly in the data including 'deny' and 'counter' options compared to expansive ones ( $\sim 43 \%$ ), suggesting that the Discussion sections in research articles require argumentation, justification and challenging others' views. While this study revealed how research authors employ interpersonal language strategies to align their audiences' views closer to the author's position, it focused more on the linguistic realizations of academic conflict rather than taking an exploratory approach in examining the functions of Engagement resources.

Meanhwile, Xu and Nesi (2019) followed a comparative approach to explore the role of cultural background on the use of Engagement in the Introduction and Conclusion sections of 30 applied linguistics research articles written by British and Chinese scholars. Using the UAM Corpus Tool, the authors examined Engagement resources in the articles individually (e.g., this may) and in combination (e.g., although this may not). Even though the two groups included different Engagement strategies in their writings, resulting in different interactive effects, there were generally more instances of heterglossic expansive markers $(52 \%)$ than contractive ones in both datasets.

Similar results were reported in Fryer's (2013) study.
Focusing on medical research articles, Fryer (2013) examined the combination of Engagement resources within sections and their variation across sections. Results reveal that varied heteroglossic Engagement items were used across and within medical RAs. Interestingly, the Discussion section had the highest number of occurrences of heteroglossic features compared to the Introduction, Methods, and Results sections. The most common heteroglossic feature across the sections and within the Discussion was entertain, (e.g., may, might, could, would), accounting for $53.80 \%$ of all heteroglossic instances in the data. A relevant finding to the present study is that while at the beginning of the Discussion section 'justify' and 'concur' resources are used, at the middle part of this section, pronounce items are included to assert the study contribution to the field. A further observation concerning the Discussion is that it likely concludes with dialogic expansion resources than dialogic contraction ones as authors usually use tentative language when noting possible areas for future research.

A similar case is found in a grant proposal analysis study done by Pascual and Unger (2010) in which they investigated Engagement items in two grant proposals in the fields of chemistry and physics written by Argentinean non-native English speakers. Focusing on the Benefits and Importance Claim sections, it was found that the proposals contained a variety of Engagement resources and were highly heteroglossic, suggesting that the academics utilized the interpersonal language choices available to them to gain acceptance from their audiences. The most frequent Engagement type used in the proposals was expansive (e.g., the results may reveal, they mentioned in a study) (63\%), indicating that the examined authors prefer to invite instead of challenging their colleagues' views.

\section{The Present Study}

As the literature review showed, only four studies have analyzed the Engagement system in research articles. Some of them looked at articles in the field of applied linguistics (Cheng \& Unsworth, 2016; Xu \& Nesi, 2019), psychology (Loi et al., 2016), and medicine (Fryer, 2013). The present study aims to extend this line of research by examining the use of Engagement in marketing research article Discussion sections to better understand how research article writers include Engagement resources to convince readers that the research contributes greatly to the field. The skillful use of Engagement choices is not an easy task, as was mentioned in the Introduction, as it requires writers to acknowledge other voices without reducing the strength of their own position (Cheng \& Unsworth, 2016; Loi et al., 2016). Identifying expert authors' preferred ways of using Engagement resources in a non-explored field, that of marketing can offer insights for academic writing materials' developers, novice researchers, and academic writing instructors. With this in mind, the present study is set out to answer the following research question: 
How do expert writers use Engagement resources in the Discussion sections of marketing research articles?

\section{Methodology}

\section{Data Collection}

To answer the research question, data was collected using a corpus-based approach. Specifically, this study constructed a corpus of nine marketing research article Discussion sections amounting to 9124 words as Table 1 shows. Six articles were drawn from International Journal of Market Research and four from Journal of Marketing (see the appendix). Both are SCOPUS ranked journals, ensuring that the quality of the collected papers is comparable. One criterion for selecting the papers was the inclusion of a separate Discussion section as it can sometimes be conflated with the results section. Therefore, all the examined articles devoted a separate section for the Discussion. The size of the corpus was limited as the context-based Engagement resources require manual analysis, resulting in the examination of every sentence in the data. However, although only nine Discussion sections were analyzed, a variety of Engagement instances were found in the dataset $(N=413)$.

Table 1. The marketing research article corpus

\begin{tabular}{|c|c|}
\hline Discussion sections & 9 \\
\hline Total number of words & 9124 \\
\hline
\end{tabular}

\section{Data Analysis}

The UAM Corpus Tool version 3.3 was used to analyze Engagement in the collected Discussion sections (O'Donnell, 2011). This free software was chosen because it facilitates the process of coding the data manually with its built-in coding schemes, and helps with analyzing the data quantitatively with its built-in statistical package. A further reason for its selection is that this corpus tool has been consistently applied in most works analyzing Engagement resources (e.g., Cheng \& Unsworth, 2016; Fryer, 2013; Geng, 2015; Xu \& Nesi, 2019), suggesting its suitability for the analysis employed in the present study. Using the UAM CorpusTool, the researcher manually annotated the data in terms of the Engagement resources shown in Figure 1. When an instance of Engagement was difficult to code, previous works were consulted to see how similar examples were coded. Following Mackey and Gass's (2005) suggestion, the researcher annotated the whole corpus twice within a two-week time interval to ensure the reliability of the coding.

The following steps were followed in the manual coding of the data. After reading the whole section, sentences which have (1) heteroglossic instance were labeled as such, and those without were labeled as (2) monoglossic. If the instance was heteroglossic, then it was either coded as (A) contractive or (B) expansive. Similarly, contractive and expensive wordings were further analyzed according to their subtypes, as illustrated in Figure 1. It should be noted that coding potential Engagement choices depended mainly on the context of their use rather than on a predetermined list of Engagement wordings. 


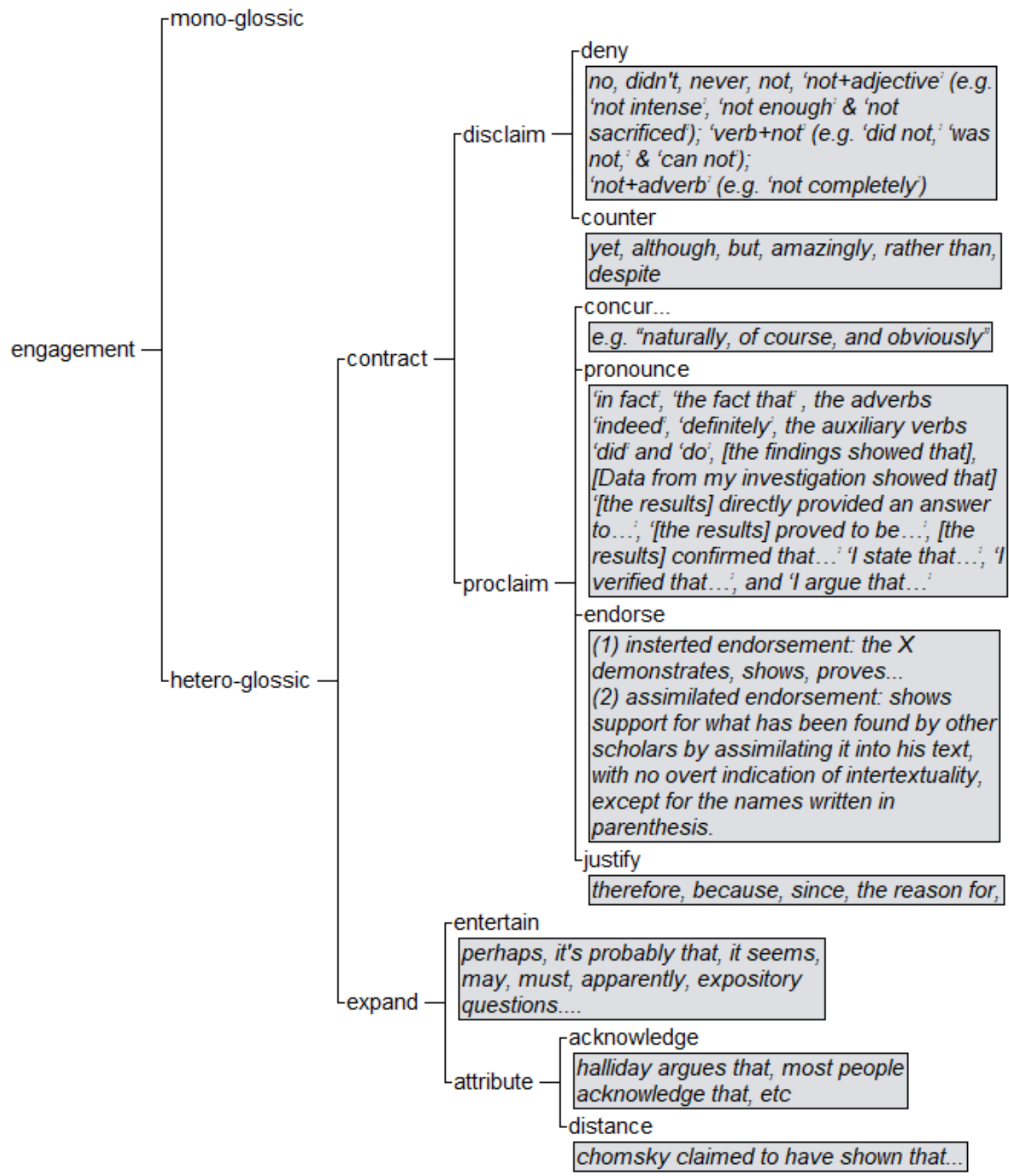

Figure 1. The Engagement coding framework (adapted from Martin and White 2005, p. 134); features are outside the grey box, example realizations are in the grey box

\section{Results}

This study is set out to investigate the use of individual Engagement resources in the Discussion sections of marketing research articles. To do this, The UAM Corpus Tool was used to analyze the data (a) qualitatively using the built-in coding scheme and (b) quantitatively using the statistics function in the software. It was expected that writers of the examined articles would successfully use Engagement resources by balancing between asserting their claims and acknowledging alternative positions found in the literature or potentially taken by readers.

Overall, Table 2 indicates that there are more heteroglossic statements (80\%) in the examined Discussion sections than monoglossic ones $(20 \%)$. This suggests that marketing research article Discussions are rich in interpersonal Engagement, and that writers in this field are more likely to acknowledge and engage with alternative views rather than presenting findings as undeniable facts that should be accepted without negotiation. 
Acknowledgment of diversity rather than ignoring it may be one of the interpersonal language features characterizing the examined research article Discussions. In other words, the higher proportion of heteroglossic items that construe a background of diverse viewpoints for the topic at hand may point to the dialogic nature of Discussion sections in the field of marketing.

Table 2. Distribution of Engagement types in the dataset

\begin{tabular}{|c|c|c|}
\hline Engagement types & Frequency & Percentage \\
\hline Heteroglossic & 412 & $80 \%$ \\
\hline Monoglossic & 102 & $20 \%$ \\
\hline Total & $\mathbf{5 1 5}$ & \\
\hline
\end{tabular}

Looking at the context of monoglossic statements in the data shows that they serve mainly to mention the aim of the study (Example A), the implemented method (Example B) or the structure of the text (Example C). The underlined words in Examples A, B and C highlight how authors may include monoglossic assertions in writing the Discussion, stating the proposition as if the reader will fully accept it and will not have a different opinion on the topic. In these cases, it seems that the writers chose to use a monoglossic sentence rather than a heteroglossic one when discussing propositional content that is not expected to invoke dispute. Thus, we see that monoglossic statements are limited to specific topics such as study aims (Example A), research instruments (Example B) and discourse structure (Example C).

A. DS2: This study has explored [monoglossic] the benefits and challenges of digital technology for marketing research as perceived by marketing researchers themselves

B. DS8: "We use [monoglossic] an array of unique and varied data sets, designs, and methods...

C. DS7: We discuss [monoglossic] these contributions next, followed by implications for managers and future research.

To understand how expert authors interpersonally position their work, the remainder of this section focuses on examining heteroglossic types and subtypes. In terms of heteroglossic types, Table 3 shows that there are more dialogic contractive instances $(66.75 \%)$ than expansive ones $(33.25 \%)$. This indicates that there is a general preference for using Engagement items that close the dialogic space, serving to refute possible counter-arguments raised by the audience to secure the writers' position and validate their presented claims. The higher frequency of heteroglossic contractive resources in the data may also be attributed to the fact that Dissection sections are where authors highlight the contributions of their study in relation to prior works and establish its importance to the field.
Table 3. Distribution of heteroglossic types in the dataset

\begin{tabular}{|c|c|c|}
\hline Heteroglossic types & Frequency & Percentage \\
\hline Contract & 275 & $66.75 \%$ \\
\hline Expand & 137 & $33.25 \%$ \\
\hline Total & $\mathbf{4 1 2}$ & \\
\hline
\end{tabular}

Further insights about the examined Dissections can be gained when analyzing heteroglossic subtypes. Table 4 highlights the most and least frequent heteroglossic subtypes in marketing research article Discussions. The following three subsections present findings separately for high, mid and low frequency subtypes in the dataset.

Table 4. Distribution of heteroglossic subtypes in the dataset ranked according to frequency

\begin{tabular}{|c|c|c|c|}
\hline \multicolumn{2}{|c|}{ Heteroglossic subtypes } & Frequency & Percentage \\
\hline 1 & Entertain & 95 & $23.06 \%$ \\
\hline 2 & Pronounce & 83 & $20.15 \%$ \\
\hline 3 & Counter & 69 & $16.75 \%$ \\
\hline 4 & Deny & 51 & $12.38 \%$ \\
\hline 5 & Endorse & 40 & $9.71 \%$ \\
\hline 6 & Acknowledge & 35 & $8.50 \%$ \\
\hline 7 & Justify & 25 & $6.07 \%$ \\
\hline 8 & Concur & 7 & $1.70 \%$ \\
\hline 9 & Distance & 7 & $1.70 \%$ \\
\hline & Total & $\mathbf{4 1 2}$ & \\
\hline
\end{tabular}

\section{High frequency Heteroglossic subtypes}

The most frequent heteroglossic subtypes are entertain, pronounce, counter and deny. All of them constitute more than $10 \%$ of all identified subtype instances in the data. Most of them are contractive resources (i.e., pronounce, counter and deny) and only one is expansive (i.e., entertain). The subsequent qualitative analysis presents the common linguistic realizations of these frequent subtypes along with some examples of their use in the Discussion sections.

Interestingly, although it was reported above that marketing research article Discussions contained more dialogic contractive wordings than expansive ones, Table 3 reveals that the most frequent heteroglossic subtype is expansive (i.e., entertain; $\mathrm{n}=95,23.06 \%$ ). This suggests that marketing academics prefer to use entertain expansive choices to open up dialogic space for opposing views compared to the other expansive subtypes such as acknowledge $(\mathrm{n}=35,8.50 \%)$ and distance $(\mathrm{n}=7,1.70 \%)$.

The examined writers used a variety of wordings to encode the entertain category. Expressions of this category included the modal auxiliary verbs 'can' $(\mathrm{n}=27,28.4 \%)$, 'may' $(\mathrm{n}=15,15.7 \%)$, 'would' $(\mathrm{n}=11,11.5 \%)$, 'could' $(\mathrm{n}=7$, $7.3 \%)$ and might $(n=6,6.3 \%)$ the modal attribute 'likely' $(\mathrm{n}=5,5.2 \%)$, the modal adjunct 'probably' $(\mathrm{n}=4,4.2 \%)$, and expository questions $(\mathrm{n}=2,2.1 \%)$. These items served 
to indicate possibility, creating a dialogic background for the proposition by presenting it as one possible idea out of many. Although most of these linguistic formulations of entertain have been reported in previous works on Engagement (e.g., Fryer, 2013; Geng \& Wharton, 2016; $\mathrm{Xu} \&$ Nesi, 2019), expressing possibility in the form of expository questions has rarely been identified and consequently discussed. Thus, they will be analyzed in detail here.

Consider the two following rhetorical questions drawn from the data in Examples D and E. The yes/no question in example D (i.e., Do...) can sometimes be seen as a leading question, requiring the reader to either agree or disagree with the point raised by the author. However, it was coded as a rhetorical rather than a leading question in the analysis as it does not seek a specific answer, but rather encouraged the reader to think about the reasoning behind consumers' actions. This question was, in fact, placed at the end of the Discussion, pointing out to the reader that there are competing views on the addressed topic and inviting them to engage with the topic as the writers did not assume that there is only one answer to their question. Meanwhile, the wh-question in example E (i.e., How...) is more open-ended and seems not to expect a specific response from the reader. Like the expository question in example D, example $\mathrm{E}$ is introduced towards the end of the section to negotiate with the reader the implications of research findings on conducting marketing research. Both of these expository or rhetorical questions seem to function to open up dialogic space to all potential views.

D. D1: Do consumers make a great effort to enter or to stay in the interactive experience because they feel they like it or because they feel that the experience is worth it? [entertain]

E. D2: How can marketing research be reorganized around these new roles? [entertain]

The second most frequent heteroglossic subtype in marketing research article Discussions is pronounce $(\mathrm{n}=83$, $20.15 \%$ ) which involve explicit authorial intervention in the text by putting more emphasis on a proposition using formulations such as "The facts of the matter are that..., We can only conclude that..." and intensifiers such as "really, indeed" (Martin \& White, 2005, p. 127). However, the examined authors in the present study used a wider range of pronounce items including 'we believe' $(\mathrm{n}=4$, $4.8 \%)$, 'we show that' $(n=3,3.6 \%)$. In fact, variability in pronounce statements makes it difficult to detect recurring pronounce items. This variation is evident in the underlined words in the following examples $(\mathrm{F}, \mathrm{G}$, and $\mathrm{H})$ from the Discussion corpus:

F. D4: Thus, we believe our results reconfirm [pronounce] this conventional wisdom.

G. D6: Our research represents [pronounce] the first attempt to identify appreciation as an additional viable symbolic recovery strategy that is often superior to the apology strategy, broadening the scope of symbolic recovery.

H. D7: This research advances [pronounce] our understanding of selling effectiveness in B2B e-negotiations...

In these examples, the writers attempted to stress that their study reconfirms prior knowledge (F), represents the first attempt to highlight an underexplored factor $(\mathrm{G})$, and advances the discipline knowledge. Using pronounce resources, such as these, allows the expert writers to emphasize the novelty of their findings while at the same time refuting any challenging position that may be held by the readers. It seems that the value of this heteroglossic subtype is that it presents the proposition as highly convincing, helping the authors to close the dialogic space for any conflicting views, and thus securing their position by establishing the originality of their work despite possible disciplinary divergence.

The third and fourth most frequent heteroglossic subtypes in marketing research article Discussions are counter $(n=69,16.75 \%)$ and deny $(n=51,12.38 \%)$. Both are in the domain of disclaim, and are used to reject a contrary proposition. Frequent linguistic realizations of counter included the adverb 'however' $(\mathrm{n}=17,4.8 \%)$, the conjunctions 'but' $(\mathrm{n}=12,4.8 \%)$, 'although' ( $\mathrm{n}=9,4.8 \%)$, 'while' ( $n=9,4.8 \%)$, and the phrase 'rather than' $(n=7$, $4.8 \%$ ). Meanwhile, deny was commonly realized in the data by the negative marker 'no' $(n=28,54.9 \%)$.

I. D9: By contrast [counter], we use data on actual transactions to classify trips into different types and correlate trip characteristics across trip types and retail formats.

J. D3: However, we do not [deny] find any effect by the demographic variables on the total acceleration and, thus, the specific target population may not [deny] have affected our results.

In Example I, the writer highlights to the reader that his study used a special kind of data that contrasts with what used in the literature, signifying the novelty of the study through using 'by contrast' to set up the observed methodological difference. In Example $J$, the writer explicitly rejects the existence of a mediating factor skewing the results by using 'not' twice, showing the accuracy of the results, and thus the quality of the research as a whole.

\section{Mid-frequency Heteroglossic subtypes}

Some heteroglossic subtypes were used moderately constituting $10 \%$ and less of all identified subtype instances in the data. The examined writers often employed in moderation endorse $(\mathrm{n}=40,9.71 \%)$ acknowledge $(\mathrm{n}=35$, $8.50 \%)$ and justify items $(\mathrm{n}=25,6.07 \%)$. These were labeled as mid-frequency subtypes as they fall between the high and low frequency categories; they are not as highly frequent nor as rarely used compared to the other two categories. Two of the mid-frequency heteroglossic 
subtypes are contractive resources (i.e., endorse and justify) while only one is expansive (i.e., acknowledge).

Both endorse and acknowledge involve presenting external voices in the text, and were used at similar rates in the Discussions. However, only the contractive endorse category presents previous works as valid and in line with the author's position. This is not the case for acknowledge, a dialogically expansive choice, as it neutrally introduces an external source without showing agreement/disagreement with that source. Consider the following two examples $\mathrm{K}$ and $\mathrm{L}$ from the data:

K. D7: For instance, parallel work in product management has examined the effect of salespeople's efforts to combine compliance-generating (e.g., "rationality") and compliance-impeding ("assertiveness") tactics on product manager compliance (Joshi 2010) [endorse].

L. D5: According to Atkins, Fiser, and Jacobs (2001) [acknowledge], the experience comes into effect after the cues have been sent to the individual.

In example K, the writer cited a prior work with a similar focus (i.e., (Joshi 2010)) to portray his research in a positive light as it is 'parallel' not identical to a published work, and thus it extends and adds to prior knowledge in the field. Here, the inclusion of the external voice limits dialogue as it increases the argumentative force of the proposition that the investigated topic is worthy of examination, guarding against any potentially different views that might undermine the value of the study. Unlike in example $\mathrm{K}$, the writer in example $\mathrm{L}$ opens up the dialogic space by citing a text-external source without overtly indicating where he/she stands with regard to that source by using the adverb; 'according to'.

Another heteroglossic subtype that occurred sporadically in the Discussions is justify. Main linguistic realizations include the subordinating conjunctions 'to' (i.e., a reduced form of in order to) $(n=6,24 \%)$ 'given' ( $n=5$, $20 \%)$, and 'because' $(\mathrm{n}=4,16 \%)$. The writers mostly used this contractive Engagement resource to explain the reasoning behind a methodological choice as example $\mathrm{M}$ below indicates.

M. D9: First, we combine Nielsen Homescan and store-level RMS data to study how [justify] the effect of changes in marketing-mix instruments on brand shares varies across both trip types and retail formats.

In this example, the reason for combining two types of data was clarified by using the reduced form of "in order to" i.e. 'to'. Doing so, allowed the writer to express the purpose of a main methodological decision in his research (i.e., to study how...), highlighting to the reader the utility of such a decision and, in turn, reducing the possibility of a counter-argument.

\section{Low-frequency Heteroglossic subtypes}

The examined marketing academics rarely used concur $(\mathrm{n}=7,1.70 \%)$ and distance $(\mathrm{n}=7,1.70 \%)$, each constituting less than $2 \%$ of all identified heteroglossic subtypes in the Discussion sections. One of them contractive (i.e., concur) and the other is expansive (i.e., distance). While concur was realized by the comment adjuncts 'certainly', 'unsurprisingly' and 'indeed' and the verb 'acknowledge', distance was primarily signaled by verbs such as 'claimed', 'overlooked', 'missed' and 'predominantly focused on', all carrying a negative assessment of prior research. The next two examples illustrate some of the linguistic formulations of concur and distance.

N. D9: Second, while we establish an empirical link between trip types and retail formats, we acknowledge [concur] that not all trips to a format are of the same type.

O. D7: Prior research has overlooked [distance] the gains from concurrent use of different influence tactics in B2B negotiations.

In $(\mathrm{N})$, the writer guesses that readers may question the empirical link established between the two analyzed factors in the research, leading him to concede to this alternative view by using the verb 'acknowledge' to show that the potential flaw in the methodology is accounted for by the author. This does not leave space for the audience as the writer acknowledges their different view on the methodology and then quickly rejects the possible limitation by using 'not'. In (O), the writer referred to the literature showing clear disagreement with it, signaled by the verb 'has overlooked'. This way, the author explicitly distances himself from the knowledge presented in external sources to point out the disregard of an important factor, 'i.e., concurrent use of different influence tactics' in the literature on B2B negotiations.

\section{Discussion}

The present study examined expert writers' ways of positioning their work in marketing research article Discussion sections to highlight how Engagement resources can be managed successfully. Using the Engagement subsystem of the Appraisal Framework, nine Discussion sections were analyzed both quantitively and qualitatively. The analysis revealed several interpersonal features of the Discussion section in marketing research articles.

One main feature is the common use of heteroglossic statements $(\mathrm{n}=421,80 \%)$ compared to monoglossic ones $(n=102,20 \%)$, indicating the highly dialogistic nature of discussions in marketing research articles. In other words, writers in this section are more likely to acknowledge and engage with alternative views either to challenge them (i.e., contract) or to invite further disciplinary discussions (i.e., expand). The tendency to include high proportions of Engagement resources in the Discussion was similarly reported in Fryer's (2013) study, noting that the Discussion 
sections in medical research articles have the highest number of heteroglossic choices. This may imply that in general, the Discussion section in research articles tends to present the textual voice as subjective and contingent, opening up the dialogic space to alternative positions and voices.

Another observed feature in the examined Discussions is the predominance of dialogically contractive Engagement resources $(n=275,66.75 \%)$ compared to dialogically expansive ones $(n=137,33.25 \%)$. Likewise, Cheng and Unsworth (2016) found that $\sim 57 \%$ of Engagement resources are contractive in applied linguistics research article Discussions. However, two studies reported different results. Both Fryer (2013) as well as Xu and Nesi (2019) found that expansive markers (52\%) are more used than contractive ones in their data. One reason for these contradictory results stems from the difference between the present study and these two works in terms of the target research article field (e.g., Fryer, 2013) and the research article section (e.g., Xu \& Nesi, 2019). For instance, Fryer (2013) examined medical articles that are a hard-knowledge discipline, unlike the soft-knowledge marketing field that usually involves more argumentation and as such "rely more on a dialogic Engagement and more explicit recognition of alternative voices" (Hyland, 2011, p. 205). The disciplinary difference in constructing knowledge in medicine (Fryer's study) and marketing (the present study) may explain the higher use of claim-making contractive Engagement resources in the present study. As for $\mathrm{Xu}$ and Nesi (2019), they examined the Introduction and Conclusion of applied linguistic research and, unlike the present study, did not investigate the Discussion, making it difficult to draw comparisons between their study and the present one.

The fact that contractive resources were used twice as much as expansive ones in the present study can be an indication that marketing academics are more concerned with establishing their credibility as knowers in the field than construing a reader-friendly text. As mentioned, contractive resources restrict the space for different views as writers use them to fend off any possible counter-argument, resulting in less space for disciplinary negotiation. A common contractive resource in the present study is pronounce $(\mathrm{n}=83,20.15 \%)$ which involve explicit authorial intervention in the text. These contrasts with Cheng and Unsworth's (2016) findings showing that deny and counter constituted most of the contractive resources in Discussions in applied linguistics research. This suggests that there seems to be more emphasis on explicit expressions of authorial voice in the marketing field; the examined authors used pronounce items primarily to highlight the importance of their work and its contribution to the field while seeking agreement for it.

Although the examined Discussions in the present study contained more heteroglossic contractive statements, the most frequent heteroglossic resource in the data is entertain $(n=95,23.06 \%)$, which expands dialogue and does not close the space for potentially challenging views. This high frequency of expressions of possibility can be interpreted as the writers' attempt to balance between asserting their own position and acknowledging others' different positions. That is, even though the examined authors included more instances of contractive items to foreground their arguments, they reduced the argumentative force of their assertions by using a considerable number of entrain items while discussing the findings. This appears to offset the effects of the minimal use of expansive resources, and this in turn constructed a subtle balance between contraction and expansion in the analyzed Discussions. It is this balance achieved by the examined writers that created a successful Discussion section as it both engaged with alternative views and challenged them in order to establish the novelty of the research and the need for it.

Nevertheless, the findings of the present study should be interpreted cautiously as it is limited in two ways. The number of Discussion sections examined in this study ( $N$ $=9$ ) is small and does not give us a representative picture of the use of Engagement resources in marketing research Discussions. Future research in this area should investigate a larger corpus of research articles Discussion sections to corroborate the present findings. Another limitation is that, despite the fact that the present study annotated the data twice in terms of Engagement resources, only one individual was engaged in this annotation process. The reliability of Engagement annotation could be ensured in works examining this interpersonal aspect in academic writing if researchers provided their coding scheme of Engagement resources on an online open-access platform (e.g., Geng, 2015).

\section{Conclusions}

This study revealed that academics in the marketing field tend to focus more on proclaiming their findings in the Discussion section while at the same mitigating the communicative force of their argument by using tentative language, creating a subtle balance between claim-making and acceptance of potentially differing views. This examination of the use of Engagement by research article writers can point how such writers successfully manage to simultaneously assert their own argument, acknowledge alternative views to it, and predict readers' response to that argument. In doing so, the results of the present study can be valuable in gaining a better understanding of Engagement in research article Discussion sections, and thus may be beneficial for those interested in this genre such as novice researchers, academic writing instructors, and material developers. 


\section{Appendix}

\section{Selected marketing research articles}

[1] Ahmed, S., \& Ting, D. H. (2020). Shopping cues: Conceptualization, scale development, and validation. International Journal of Market Research, 62(1), 95-112. https://doi.org/10.1177/1470785319861897

[2] Borah, A., Banerjee, S., Lin, Y. T., Jain, A., \& Eisingerich, A. B. (2020). Improvised Marketing Interventions in Social Media. Journal of Marketing, 84(2), 69-91. https://doi.org/10.1177/0022242919899383

[3] Chen, H., Wang, R., \& Liang, X. (2020). Demystifying engagement: Chinese advertising practitioners' perspective. International Journal of Market Research, 1-21. https://doi.org/10.1177/1470785320905273

[4] Cluley, R., Green, W., \& Owen, R. (2019). The changing role of the marketing researcher in the age of digital technology: Practitioner perspectives on the digitization of marketing research. International Journal of Market Research, 62(1), 1-16. https://doi.org/10.1177/1470785319 865129

[5] Höhne, J. K., Revilla, M., \& Schlosser, S. (2019). Motion instructions in surveys: Compliance, acceleration, and response quality. International Journal of Market Research, 62(1), 1-15. https://doi.org/10.1177/1470785319858587

[6] Jindal, P., Zhu, T., Chintagunta, P., \& Dhar, S. (2020). Marketing-Mix Response Across Retail Formats: The Role of Shopping Trip Types. Journal of Marketing, 84(2), 114 132. https://doi.org/10.1177/0022242919896337

[7] Singh, S. K., Marinova, D., \& Singh, J. (2020). Business-to-Business E-Negotiations and Influence Tactics. Journal of Marketing, 84(2), 47-68. https://doi.org/10.1177 /0022242919899381

[8] Wu, X. X., Choi, W. J., \& Park, J. (2019). "I" see Samsung, but "we" see Samsung and LG: The moderating role of consumers' self-construals and perceived similarity in spillover effect of product-harm crisis. International Journal of Market Research, 62(1), 1-16. https://doi.org/10.1177/14 70785319866404

[9] You, Y., Yang, X., Wang, L., \& Deng, X. (2020). When and Why Saying "Thank You" Is Better Than Saying "Sorry" in Redressing Service Failures: The Role of Self-Esteem. Journal of Marketing, 84(2), 133-150. https://doi.org/10.11 $77 / 0022242919889894$

\section{REFERENCES}

[1] Chatterjee, M. (2008). Textual engagement of a different kind? Bridging Discourses: ASFLA 2007 Online Proceedings, 1-15. Australia: Australian Systemic Functional Linguistics Association.

[2] Cheng, F., \& Unsworth, L. (2016). Stance-taking as negotiating academic conflict in applied linguistics research article discussion sections. Journal of English for Academic Purposes, 24, 43-57.
[3] Fryer, D. (2013). Exploring the dialogism of academic discourse: Heteroglossic Engagement in medical research articles. In G. Anderson \& K. Bech (Eds.), English corpus linguistics: Variation in time, space and genre (pp. 183207). Amsterdam - New York: Rodopi.

[4] Geng, Y. (2015). Appraisal in discussion sections of doctoral theses in the discipline of ELT/Applied Linguistics at Warwick University: a corpus-based analysis (doctoral dissertation). University of Warwick.

[5] Geng, Y., \& Wharton, S. (2016). Evaluative language in discussion sections of doctoral theses: Similarities and differences between L1 Chinese and L1 English writers. Journal of English for Academic Purposes, 22, 80-91.

[6] Hyland, K. (2005). Stance and engagement: a model of interaction in academic discourse. Discourse Studies, 7(2), 173-192.

[7] Hyland, K. (2011). Disciplines and discourses: Social interactions in the construction of knowledge. In $\mathrm{D}$. Starke-Meyerring, A. Pare, N. Artemeva, M. Horne, \& L. Yousoubova (Eds.), Writing in knowledge societies (pp. 193-214). Fort Collins, CO: The WAC Clearinghouse and Parlor Press.

[8] Loghmani, Z., Ghonsooly, B., \& Ghazanfari, M. (2020). Engagement in Doctoral Dissertation Discussion Sections Written by English Native Speakers. Journal of English for Academic Purposes, 100851.

[9] Loi, C.-K., Lim, J. M.-H., \& Wharton, S. (2016). Expressing an evaluative stance in English and Malay research article conclusions: International publications versus local publications. Journal of English for Academic Purposes, 21, $1-16$.

[10] Mackey, A., \& Gass, S. M. (2005). Second language research: Methodology and design. Mahwah, NJ: Lawrence Erlbaum.

[11] Martin, J. R., \& White, P. R. (2005). Language of evaluation: Appraisal in English. London: Palgrave Macmillan.

[12] Mei, W. S., \& Allison, D. (2007). Evaluative expressions in analystical arguments: aspects of appraisal in assigned English language essays. Journal of Applied Linguistics and Professional Practice, 2(1), 105-127.

[13] O’Donnell, M. (2011). CorpusTool (version 3.3). Retrieved 25 February 2020, from http://www.corpustool.com/downlo ad.html.

[14] Oskoz, A., Gimeno-Sanz, A., \& Sevilla-Pavón, A. (2018). Examining L2 Learners' Use of Engagement Strategies in Telecollaborative Written Interactions. In B. Mousten, S. Vandepitte, E. Arnó, and B. Maylath, B. Mousten, S. Vandepitte, ... B. Maylath (Eds.), Multilingual Writing and Pedagogical Cooperation in Virtual Learning Environments (pp. 200-220). IGI Global.

[15] Pascual, M., \& Unger, L. (2010). Appraisal in the research genres: An analysis of grant proposals by Argentinean researchers. Revista Signos, 43(73), 261-280.

[16] Ryshina-Pankova, M. (2014). Exploring argumentation in course-related blogs through engagement. In G. Thompson \& L. Alba-Juez (Eds.), Evaluation in Context (pp. 281-302). Amsterdam and Philadelphia: John Benjamins. 
[17] Thompson, D. K. (1993). Arguing for experimental "facts" in science. Written Communication, 10(1), 106-128.

[18] Thompson, G. (2001). Interaction in academic writing: Learning to argue with the reader. Applied Linguistics, 22(1), 58-78.

[19] White, P. (2011). Appraisal. In J. Zienkowski, J.-O. Östman, \& J. Verschueren (Eds.), Handbook of Pragmatics (pp. 1436). Amsterdam: John Benjamins.

[20] Widhiyanto. (2017). Arguments in Academic Writing: Linguistic analysis of arguments constructed in undergraduate dissertations written by student writers from difference academic contexts (doctoral dissertation). School of Education, University of Wollongong.

[21] Xu, X., \& Nesi, H. (2019). Differences in engagement: A comparison of the strategies used by British and Chinese research article writers. Journal of English for Academic Purposes, 38, 121-134. 